\title{
Notch pathway is required for protection against heat-stress in spermatogonial stem cells
}

\section{Omar D. Moreno Acosta1, Agustín F. Boan1, Ricardo S. Hattori2, Juan I. Fernandino1§}

1 Laboratorio de Biología del Desarrollo - Instituto Tecnológico de Chascomús. INTECH (CONICET-UNSAM), Argentina.

2 Salmonid Experimental Station at Campos do Jordão, UPD-CJ, Sao Paulo Fisheries Institute (APTA/SAA), Campos do Jordão, Brazil

$\S$ Corresponding author: JIF (fernandino@intech.gov.ar)

ORCID: RSH (0000-0003-2605-6718), JIF (0000-0003-1754-2802)

\section{Keywords}

Presenilin enhancer-2; Germline; Testis; Medaka

\begin{abstract}
Environmentally favorable conditions the sustainability of spermatogenesis is brought about by a balance between two types of division, the self-renewal division for the maintenance of the stem cell pool and the differentiation division for continuous production of spermatozoa. The production of gametes under unfavorable, stressful conditions can decrease or even be interrupted, compromising fertility parameters. Thus, the survival of spermatogonial stem cells (SSCs) is crucial for the recovery of spermatogenesis after stressful situations (e.g. high temperature). Here, we show that the Notch pathway protects the spermatogonial stem cells against thermal stress, ensuring reproductive success after normal conditions are restored. First, presenilin enhancer-2 (pen-2), the catalytic subunit of $\gamma$-secretase complex, was localized in SSCs of the medaka testis. The exposure of adult males to thermal stress condition induced apoptosis in all spermatogenics cells, with the exception of SSCs. Concomitantly, the Notch pathways was up-regulated, including the pen-2, its ligands (dll4, jag1-2) and its receptors (notch1a-3); pen-2 expression was restricted to the SSCs during thermal stress. The importance of this pathway was further supported by an ex vivo approach, in which the inhibition of Notch activity induced a loss of SSCs. Overall, this study demonstrates that the Notch pathways activity is necessary for the protection of SSCs under chronic thermal stress.
\end{abstract}




\section{Introduction}

Spermatogenesis is a cellular process necessary for the formation of male gametes from spermatogonial stem cells (SSCs), which proliferate synchronically and differentiate into millions of spermatozoa (SZ) or are constantly self-renewed asynchronically, like other stem cells $[1,2]$. To maintain continuous spermatogenesis throughout the male reproductive life, SSCs reside in the "niche", a specialized microenvironment of the testes, which regulates their properties of self-renewal, pluripotency, quiescence, size, and their ability to differentiate and proliferate [3-6]. This ability of the niche to maintain SSCs homeostasis is what allows them to survive under adverse conditions.

Temperature is one of the most relevant environmental factors that have a strong effect on reproduction. This is due to the fact that it affects both the early development of the testes, as well as in adult stages the quality and quantity of gametes, thus compromising spermatogenesis and reproductive success [7-12]. In various groups of vertebrates, it has been studied how hyperthermia deteriorates the different types of germ cells [13], mainly due to apoptosis [14]. In several vertebrates and particularly in fish, it has been observed that under high temperatures only SSCs remain as a remnant, which have the ability to regain the germ line $[15,16]$. This reversible characteristic that allows the germ line to overcome a stress factor, and the interaction of SSCs in the niche, made us hypothesize that the protection of germ cells must occur by a direct signaling between the niche and germ cells, which regulate this process.

In this sense, despite countless studies, it is still difficult to characterize the somatic stem niche in vertebrates [17]. Recent studies in early development of mice have been able to show a possible somatic stem niche [18], and much progress has also been made in other model organisms, like flies [5, 6]. In both cases, it was observed that one of the main signaling pathways involved is the Notch pathway. This is a highly conserved juxtacrine signaling pathway well characterized in other processes in mammals, mainly proliferative, and is composed of four receptors (Notch1-4) that interact with their ligands or others with similar structure, delta 1, 3-4, jagged1-2 $[19,20]$. After binding to the ligand, in the canonical Notch signal pathway, the receptor is activated by the $\gamma$-secretase complex, mainly by the presenilin enhancer-2 (Pen-2) catalytic subunit, where proteolysis occurs within the transmembrane domain that releases the intracellular domain (Notch intracellular domain, Nicd) [21-23]. After cleavage, Nicd is translocated to the nucleus and associates with DNA-binding proteins, such as CSL (later CBF1), to activate transcription of cis target genes, such as hes 1 and hes5 [24], that in general inhibit the expression of other genes [25]. Moreover, the participation of Notch signal, particularly Notch1, in the regulation of gonocytes quiescence has been well characterized in Sertoli cells [26]. Despite the numerous studies on the Notch pathway in the regulation of cell proliferation, little is known about its participation in the regulation of the proliferation of germ cells under an environmental stressor, such as temperature.

On these regards, in a previous study it was suggested that Pen-2 act as an anti-apoptotic gene, protecting germ cell gonocytes from temperature during testis differentiation in pejerrey fish [27]. This catalytic member of the $\gamma$-secretase complex has been shown to play an important function in the survival of cells, protecting them from apoptosis [28]. Selective knock-down of pen-2 in developing zebrafish embryos resulted in strong induction of the p53-dependent apoptosis cascade in whole animal [29]. Although the function of Pen-2 has been highly studied in brain, especially in Alzheimer's disease $[21,30]$ and cancer [31], its participation on the 
gonad has not been fully elucidated, especially during high temperature exposure. As in fish, it has also been established that mammalian germ cells experience apoptosis via the p53 cascade during exposure to high temperatures [32]; however, germ cells, such as other stem cells [33], have a protective mechanism to avoid the induced apoptosis damage by entering a transient state of cell-cycle quiescence. Therefore, the germ cells must retain the appropriate information and totipotency, recovering later the reproduction [34].

Based on these antecedents, we considered to evaluate whether this cell-to-cell communication is involved in the mechanism of protection of germ cells against thermal stress.

\section{Materials and Methods}

\section{Source of medaka}

All experiments were performed with adults of medaka Oryzias latipes from hi-medaka strain (ID: MT835) supplied by the National BioResource Project (NBRP). These fish were kept under controlled laboratory conditions for this species [35]. Briefly, fish were reared at $26^{\circ} \mathrm{C}+/-1$ under a photoperiod of 14 light hours 8 of darkness. For the temperature stress experiment, the temperature in $10 \mathrm{~L}$ fish tank was raised to $33{ }^{\circ} \mathrm{C}+/-1$ for 30 days. During the time that the experiment elapsed, the control group remained in the aforementioned initial conditions. Fish from each group had their testes removed for subsequent analysis at 3, 10, and 30 days after the beginning of the experiment. The control group was kept under normal conditions of the rearing room $25^{\circ} \mathrm{C}+/-1$ (Figure 1E). Fish were handled in accordance with the Universities Federation for Animal Welfare Handbook on the Care and Management of Laboratory Animals (www.ufaw.org.uk) and internal institutional regulations.

\section{Ex vivo experiments with DAPT}

To carry out ex vivo experiment with the testicular sections, the fish were anesthetized by freezing on ice and then euthanized. The testes were then dissected under the stereoscope, using forceps and sterile scissors. The gonads were removed and placed in $1 \mathrm{M}$ phosphate buffer saline (PBS) with $1 \mathrm{x}$ streptomycin penicillin (Gibco). They were then rinsed and subsequently cut into pieces of about one millimeter. These were left overnight at $25^{\circ} \mathrm{C}$, in L15 medium (Gibco) with antibiotic (Figure 4A). Then, 2 to 4 pieces of testis were placed in each well with $1 \mathrm{ml}$ of medium with the DAPT drug (Selleckchem), a $\mathrm{y}$-secretase inhibitor and indirectly an inhibitor of Notch, at a concentration of $12.5 \mu \mathrm{M}$ and $25 \mu \mathrm{M}$. As a control, the drug diluent was placed DMSO and incubated for 24 hours in a Fisher thermo stove.

\section{Total RNA Extraction and Realtime-PCR}

Testes were removed from males for gene expression analysis. Total RNA extraction was carried out using $300 \mu \mathrm{L}$ of TRIzol $($ Reagent (Invitrogen), according to the manufacturer's instructions. RNA from each sample (500 ng) was used to perform the cDNA synthesis using the SuperScript II enzyme (Invitrogen).

Real-time PCR primers are listed in Table Supplement 1. Gene-specific qPCR was performed using the SYBR green master mix (Applied Biosystem). The amplification protocol consisted of an initial cycle of $1 \mathrm{~min}$ at $95^{\circ} \mathrm{C}$, followed by $10 \mathrm{~s}$ at $95^{\circ} \mathrm{C}$ and $30 \mathrm{~s}$ at $60^{\circ} \mathrm{C}$ for a total 40 cycles. The subsequent quantification method was performed using the 2- $\Delta \Delta \mathrm{Ct}$ method (threshold cycle; assets. thermofisher.com/TFS-Assets/LSG/manuals/ cms_040980.pdf) and normalized against reference gene values for ribosomal protein L7 (rp/7) [36].

\section{Histology and immunofluorescence}

Samples for histology and IF were firstly fixed in Bouin's solution. Then they were embedded in 
paraffin and transversally sectioned on a Leica DM 2125RT microtome at 4-5 $\mu \mathrm{m}$ thickness.

For IF, sections were washed with $0.1 \mathrm{M}$ PBS $(\mathrm{pH} 7.4)$ and blocked in $0.1 \mathrm{M}$ PBS containing $0.5 \%$ bovine serum albumin (Sigma-Aldrich) and 0.5\% Triton X100 for 60 min before overnight incubation at $4^{\circ} \mathrm{C}$ with primary antibody, anti-pen-2 antibody (1:200, rabbit, LS-C135520, LSBio). A negative control was also run to see specificity without primary antibody. After incubation, the sections were washed twice in PBS and incubated at RT for 90 min with Alexa Fluor 488-conjugated goat antirabbit IgG (ThermoFisher Scientific, A-11008) secondary antibodies at a dilution of 1:2000 in PBS. After incubation, sections were rinsed twice with PBS and mounted with Fluoromount mounting medium (Sigma-Aldrich) containing 4',6diamidino-2-phenylindole (DAPI, $5 \mu \mathrm{g} / \mathrm{ml}$, Life Technologies).

\section{TUNEL assay}

The presence of apoptosis in gonad was detected through the In situ Cell Death Detection Kit, Fluorescein (Roche). Samples fixed in Bouin's solution, embedded in paraffin and sagittal sectioned at $5 \mu \mathrm{m}$ were treated according to the manufacturer's manual, with a step of permeabilization with $0.1 \%$ Triton $X-100,0.1 \%$ sodium citrate in PBS $1 \mathrm{X}$ solution. Fluorescein was observed under a Nikon Eclipse E600 microscope.

\section{RNA in situ hybridization}

ISH were performed as previously described [37].

Briefly, digoxigenin-labeled probes were synthesized from the full-length medaka cDNA of oct-4 (stem cell marker also known as pou5f1; [38]) using pGEM®-T Vector (Promega) linearized plasmid. Testicular explants from ex vivo treatment was fixed overnight in $4 \%$ RNAse-free paraformaldehyde (PFA) at $4^{\circ} \mathrm{C}$, permeabilized using $20 \mu \mathrm{g} / \mu \mathrm{l}$ proteinase $\mathrm{K}$ at room temperature (RT), and hybridized at $68^{\circ} \mathrm{C}$ overnight with oct-4 digoxigenin (DIG)-labeled RNA probes. Hybridized probes were detected using an alkaline phosphatase-conjugated anti-digoxigenin antibody (1:2000; Roche) in the presence of nitro blue tetrazolium/5-bromo-4-chloro-3'-indolyphosphate substrates (Roche). Stained testicular explants were embedded in gelatin, cryostat sectioned at 14-16 $\mu \mathrm{m}$ thickness and photographed.

\section{Statistical analysis}

Values are presented as mean \pm standard error of the mean (SEM) for continuous variables and as percentages for categorical variables. Fold change and statistical analysis of RT-qPCR quantifications were performed using FgStatistics software (http:// sites.google.com/site/fgStatistics/), based in the comparative gene expressions method [39]. Statistical analyses were performed by using Prism 9 (GraphPad Software, San Diego, CA). Continuous variables were compared by one-way analysis of variance (ANOVA), followed by Tukey's multiple comparisons test, for compare the mean of each column with the mean of every other column. All differences were considered statistically significant when $p<0.05$.

\section{Results}

\section{Identification of Pen-2 in adult testis}

The presence of Pen-2 immuno-reactive cells were observed in the distal portion of the lobule of the testis, the same germinal region of type $A$ spermatogonia (SGa), or spermatogonial stem cell (SSCs) (Figure 1A, B). To verify the co-localization of Pen-2 with SGa, an ISH with oct-4 riboprobe was performed. Ir-Pen-2 cells were observed sorrounding SGa (oct-4 positive cells) (Figure 1C, D), establishing that Pen-2 is expressed in somatic cells.

\section{Up-regulation of gonadal Pen-2 at high temperature}

Then, we analyzed the expression of Pen-2 /pen-2 (protein and transcript) in an in vivo adult treatment, keeping adult males at normal (NT- $25^{\circ} \mathrm{C}$ ) and high 


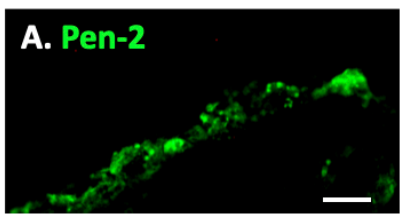

E. Experimental design
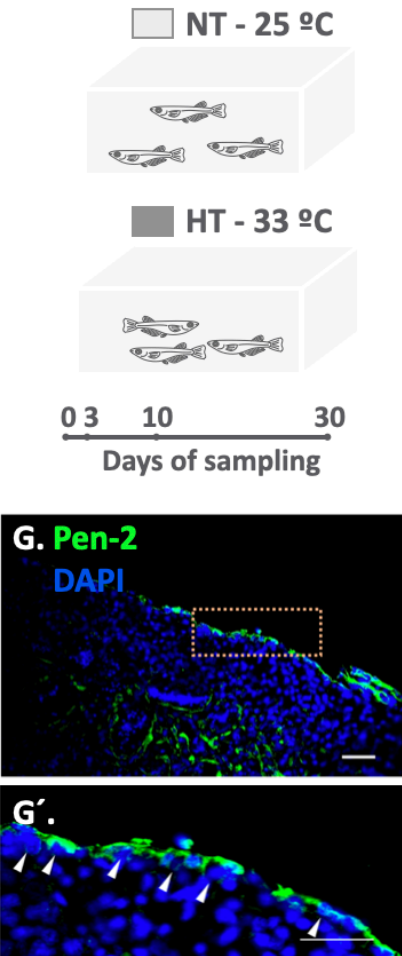

NT - 0 days
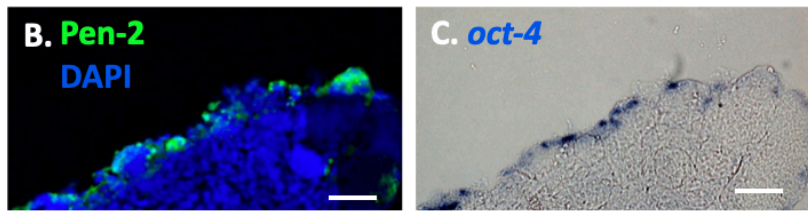

F. Notch pathway

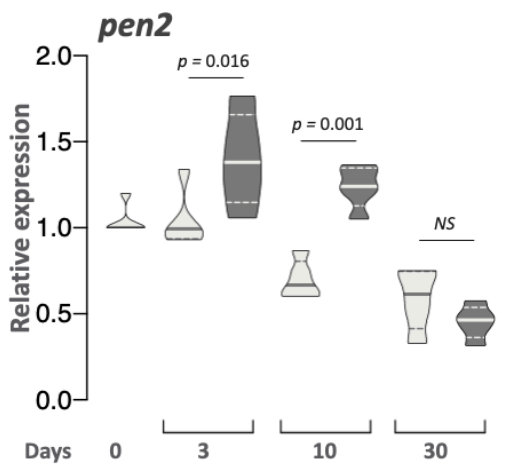

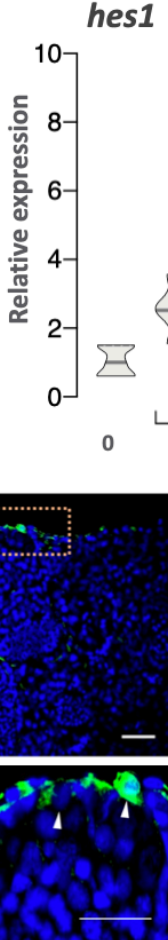

HT - 10 days

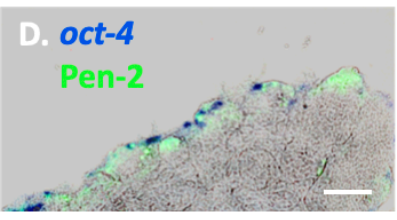

hes1
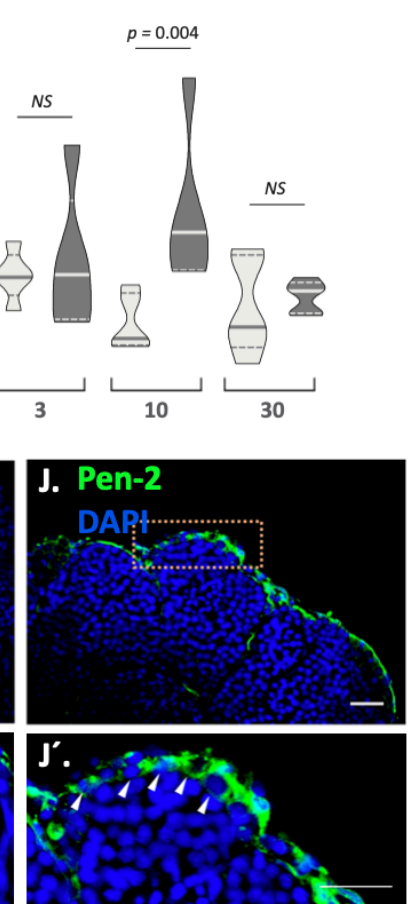

HT - 30 days

Figure 1: Pen-2 is down-regulated during thermal treatment in male. Transversal sections of the distal portion of the testis lobule, observing Pen-2 (green, immunofluorescence, IF) and nuclei stained with DAPI (blue) (A, B). Co-localization of Pen-2 (green, IF) with oct-4 (blue, in situ hybridization) (C, D). Experimental design, in which adult males were reared at control (NT $-25^{\circ} \mathrm{C}$, light grey) and high $\left(\mathrm{HT}-33^{\circ} \mathrm{C}\right.$, dark grey) temperature (E). Notch pathway: Transcript abundance levels of pen-2 and hes 1 in different treatment days of treatment, 0, 3, 10 and 30 days. (F). IF of Pen-2 (green) in testis of male reared at HT at $0(\mathbf{G}), 3(\mathbf{H}), 10$ (I) and 30 (J) days of thermal treatment, and nuclei stained with DAPI (blue). Magnification of each testis, doted orange line, at different sapling time of at $0\left(\mathbf{G}^{\prime}\right), 3\left(\mathbf{H}^{\prime}\right), 10\left(\mathbf{I}^{\prime}\right)$ and $30\left(\mathbf{J}^{\prime}\right)$ days of thermal treatment. SGa are indicate with arrowhead $\left(\mathbf{G}^{\prime}-\mathbf{J}\right)^{\prime}$. Scale bar represents 20 $\mu \mathrm{m}$. Transcript abundance quantification was performed using the 2- $\Delta \Delta \mathrm{Ct}$ method and pen-2 and hes 1 values were normalized to rp/7. $p$-values are indicated when transcript abundance between treatment at the same sampling day differ significantly $(P<0.05)$. NS, not statistically significant. Relative gene expression levels were compared as described by Pfaffl [39].

temperature $\left(\mathrm{HT}-33^{\circ} \mathrm{C}\right)$ for 30 days (Figure 1E). Firstly, we quantified the transcript abundance of Notch pathway related genes, such as pen-2 and hes-1 (a well know Notch effector [20]). Both genes are up-regulated at $\mathrm{HT}$ at 3 and 10 days of treatment, showing no differences at the end of the experiment (30 days) with NT (Figure 1F).

Additionally, we characterized the localization of the Pen-2 in testis of fish reared at high temperature. At the beginning of treatment (NT - 0 days) Pen-2 showed an expression in somatic cells surrounding SGa of the distal portion of the lobule, and in the medullar region of the testis, probably somatic cells surrounding spermatids in the medullar region (Figure 1G, G'). Interestingly, under high temperature treatment the expression of Pen-2 is restricted to the distal portion of the lobule, where are the SGa (Figure 1 $\mathbf{H}-\mathbf{J}, \mathbf{H}^{\prime}-\mathbf{J}$ )'.

\section{Apoptosis of testis germ line at high temperature}

Is well know that increasing temperature induce the inhibition of spermatogenesis, with germ cell line loss. Here, high temperature during 3 days did not affect the germ line of adult males, observing spermatozoas $(\mathrm{Sz})$ in the lumen of the testis (Figure 2A). However, later, after 10 days of heat-treatment, 


\section{A. Histology}

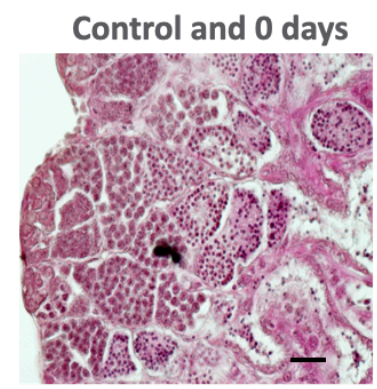

B. Apoptosis pathway

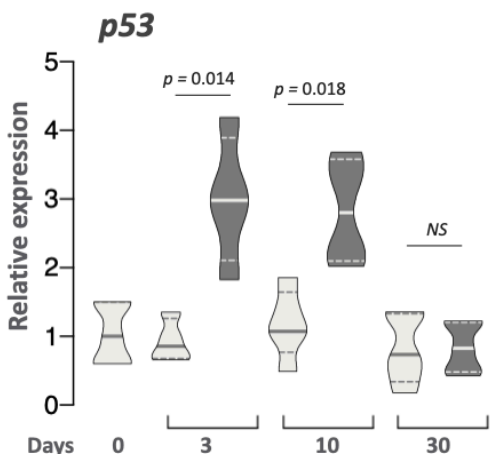

D. TUNEL assay

Control and 0 days

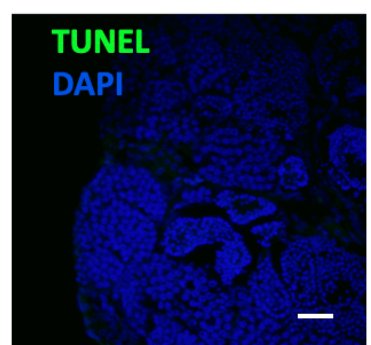

3 days

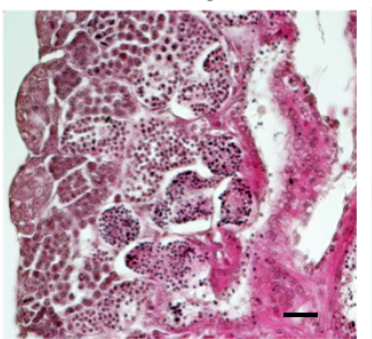

bcl2

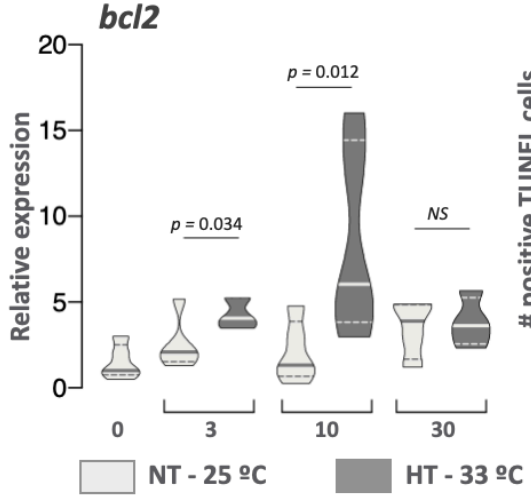

3 days

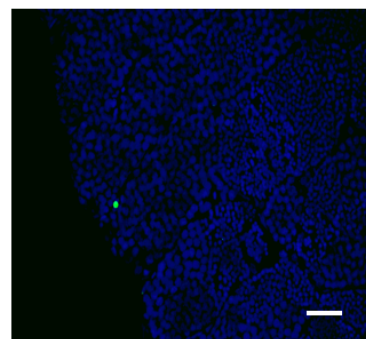

10 days

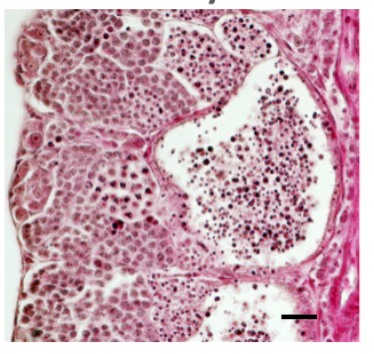

30 days

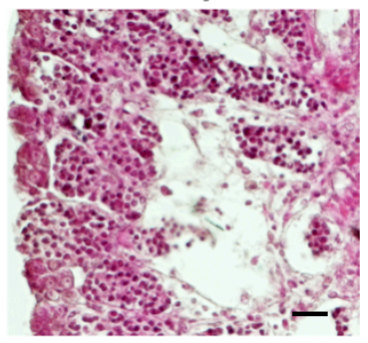

\section{Apoptotic cells (TUNEL)}

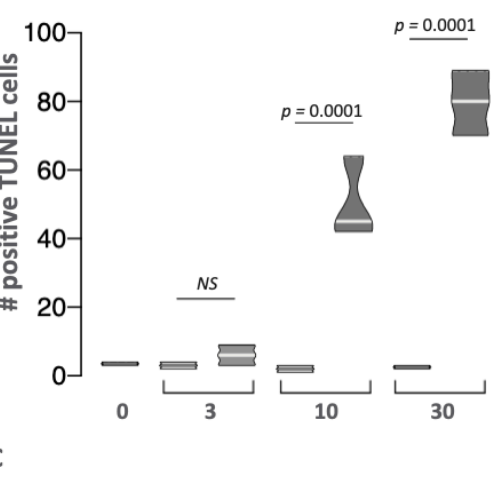

Figure 2. High temperature induces apoptosis of testis germ line. Histology: Transversal sections of the testis staining with eosin and hematoxylin (E\&H) (A) of adult male reared at $\mathrm{HT}$ during 0 (and control), 3, 10 and 30 days. germ cell line loss. Apoptotic pathway: Quantification of $p 53$ and $b c / 2$ transcript abundance at $0,3,10$ and 30 days in testis of males reared at normal (NT $-25^{\circ} \mathrm{C}$, light grey) and high ( $\mathrm{HT}-33^{\circ} \mathrm{C}$, dark grey) temperature (B). Apoptotic cells: Quantification of apoptotic cells by TUNEL assay at different sampling time and thermal treatment (C). TUNEL assay: Transversal section of the testis with TUNEL assay showing apoptotic cells (green) and nuclei stained with DAPI (blue) at 0 (and control), 3, 10 and 30 days (D). Scale bar represents $20 \mu \mathrm{m}$. Transcript abundance quantification was performed using the $2-\Delta \Delta \mathrm{ct}$ method and $p 53$ and $b c / 2$ values were normalized to $r p / 7$. $p$ values are indicated when transcript abundance between treatment at the same sampling day differ significantly $(P<0.05)$. NS, not statistically significant. Relative gene expression levels were compared as described by Pfaffl [39] to (B); Tukey's multiple comparisons test per (C).

we observed shorter seminiferous tubules, apparently due loss of sperm production and a large number of spermatocytes, with enlargement of the lumen. Finally, at 30 days, we observe that germ line was altered, whit low or even absent of sperm number was observed, presenting fibrosis in the medullar region. However, throughout the treatment, a large number of SSCs was observed in the testis.

To evaluate whether the temperature treatment is causing the loss of germ line, we decided to evaluate apoptosis in the heat-treatment. The apoptotic pathway, quantified by $p 53$ and bc/2 gene showed the same pattern of pen-2, with an upregulation in $\mathrm{HT}$ testis at 3 and 10 days in comparation to NT (Figure 2B), establishing that the heat-treatment induced apoptosis. Finally, to corroborate the loss of germ line by high temperature we quantified apoptosis by TUNEL assay. We observed that the loss of the germ line is caused by apoptosis for 10 days of treatment, 
A.

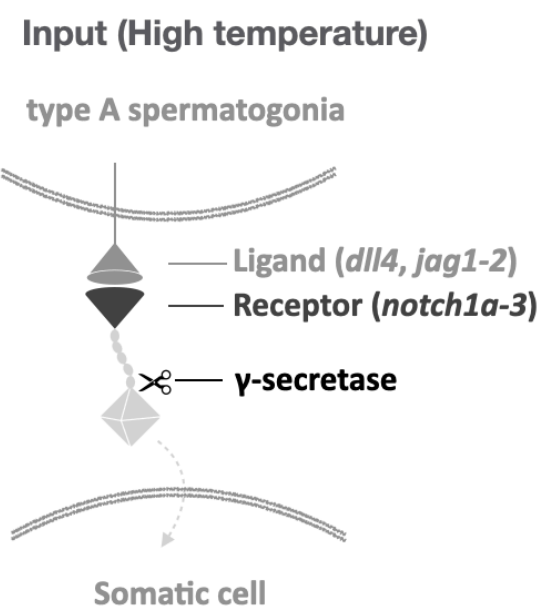

Output (quiesence of Sga)
B.

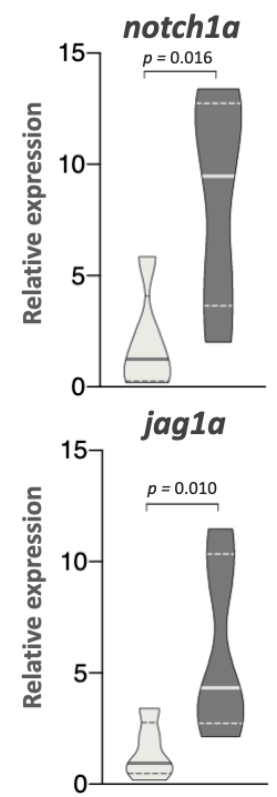

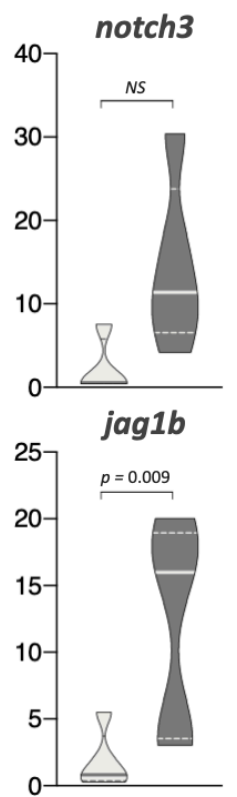

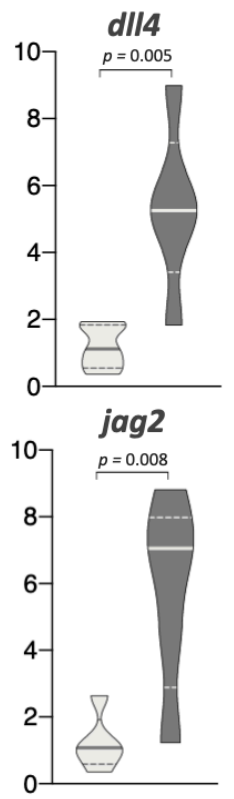

NT - $25 \circ C$

HT - 33 으

Figure 3. Notch pathway is up-regulated in testis at 10 days of heat treatment. Presumptive Notch cell-to-cell signaling between type A spermatogonia and Sertoli cell under a high temperature input (modified from Henrique \& Schweisguth [20]) (A). Quantification of different Notch pathway ligand (dll4, jag1a-b, jag2-2b) and receptors (notch1a, 3) transcript abundance at 10 days in testis of males reared at normal (NT $-25^{\circ} \mathrm{C}$, light grey) and high ( $\mathrm{HT}-33^{\circ} \mathrm{C}$, dark grey) temperature (B). Transcript abundance quantification was performed using the $2-\Delta \Delta \mathrm{Ct}$ method and values were normalized to $\mathrm{rp} / 7$. $\mathrm{p}$-values are indicated when transcript abundance between treatment at the same sampling day differ significantly $(P<0.05)$. NS, not statistically significant. Relative gene expression levels were compared as described by Pfaffl [39].

showing an increased number of positive tunnel cells (Figure 2C, D). Moreover, at 30 days, the number of cells positive tunnel is higher compared to the control group. This greater number of apoptotic cells are found in the medullar region of the testis, whereas no apoptotic cells were observed in the peripheral region of the tubule, where oct4positive cells or SGa are observed (Figure 2D).

\section{Activation of Notch pathway in testis under high temperature}

Taking into account the expression of Pen-2/pen-2 and hes1, two key players in the Notch pathway, in testes kept at high temperature, we decided to measure the transcript levels of ligands and receptors of this pathway at 10 days of treatment (Figure 3A). The transcript abundance of the ligands dll4, jag1a, jag1b and jag2, as well as the receptor notch-1a were up-regulated at high temperature compared to the controls (Figure 3B). Otherwise, notch3 and jag2b did not show significant differences (Figure 3B).

\section{Inhibition of Notch pathway in ex vivo}

\section{testis explants at high temperature}

After observed an up-regulation of Notch pathway with restriction of Pen-2 in the SGa region of the distal lobule, our next step was inhibited this pathway under high temperature treatment. Given the complexity of the Notch pathway and how it affects the fate of many cell types in different tissues, we decided to use an ex vivo testis explants approach to analyze the protective role of this cellto-cell signaling. Initially, we detected that apoptosis was induced from 3 hours of exposure, observing the up-regulation of p53 (Figure Supplement 1A). Moreover, no differences were observed between 3, 12 and 24 hours of high temperature exposure. Additionally, dose-response curve showed that 12.5 (moderate down-regulation of hes1) and $25 \mu \mathrm{M}$ (high inhibition of hes1) of the Notch inhibitor DAPT were the best condition to block the Notch action (Figure Supplement 1B). 
A.
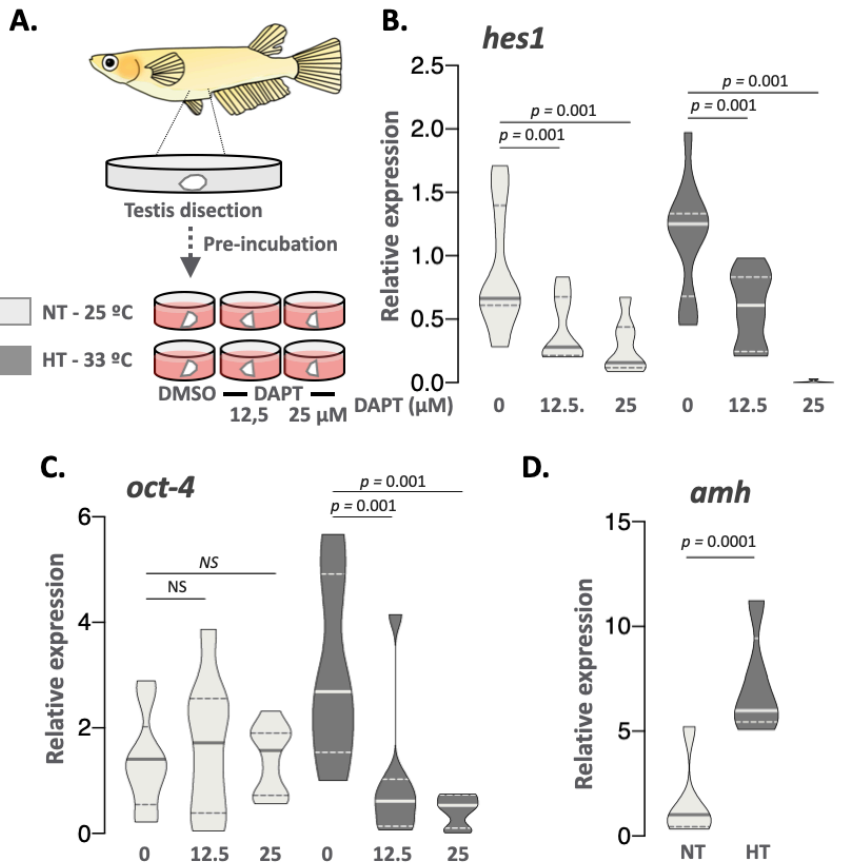

D.

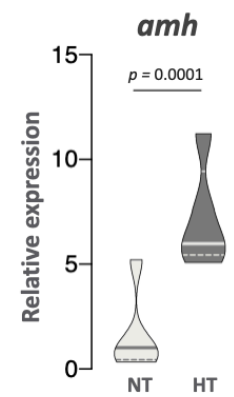

Figure 4. Notch pathway protects type A spermatogonia to heat-induced loss. Experimental design of ex vivo approach, in which adult testis explants were incubated during 24 hours at control (NT $-25^{\circ} \mathrm{C}$, light grey) and high (HT $-33^{\circ} \mathrm{C}$, dark grey) temperature with DAPT ( $\gamma$-secretase inhibitor; 12,5 and $25 \mu \mathrm{M})$ by triplicated (A). Transcript abundance levels of hes1 (B, Notch pathway cis target genes) and oct-4 (C, stem state marker gene) to different treatments. Transcript abundance of amh of testis explant incubated at NT and HT during 24 hours (D, germ cell proliferation inhibitor). Transcript abundance quantification was performed using the $2^{-\Delta \Delta \mathrm{Ct}}$ method and pen-2 and hes 1 values were normalized to rp/7. $\mathrm{p}$-values are indicated when transcript abundance between treatment at the same sampling day differ significantly $(\mathrm{P}<0.05)$. NS, not statistically significant. Relative gene expression levels were compared as described by Pfaffl [39].

Then, we observed that hes1 was down-regulated in a dose-dependent manner, at both normal and high temperature when ex vivo testis explants were treated with DAPT (Figure 4B), showing that Notch pathway was inhibited. Interestingly, the expression of the stem state marker gene oct-4 was affected only by temperature treatment (Figure 4C), suggesting a reduction in the SGa and a necessary protective effect of Notch on germ cell fate under thermal stress.

In the next step the protective effects of Notch pathway at high temperature exposure in avoiding the loss of SGa after 24 hours of incubation was analyzed. Since no apoptosis in SGa was observed in the in vivo temperature experiment (Figure 2A), we studied SGa quiescence by means of the levels of the Amh, a germ cell proliferation inhibitor [40].
We observed that the levels of amh increase significantly when the testes are subjected to heat stress (Figure 4D), suggesting that the increase in temperature promotes the quiescence of the germ cells through the activation of the Notch pathway.

\section{Discussion}

In the last decades a decrease in the seminal parameters of men has been observed, mainly attributed to changes in behavior, as well as to increases in temperature [41, 42], which is a well-known stressor that disrupts spermatogenesis even in fish. Once the stressful condition is overridden, the recovery of spermatogenesis is a necessary mechanism to ensure the continuity of reproduction of an individual. This can be achieved because spermatogonia, which are stem cells, shift to a quiescence state in order to protect themselves from the harmful environment [43]. Despite the reproductive importance of recovery of spermatogenesis after stress, the molecular regulators that protects these germ stem cells against an increase in temperature have not been fully elucidated. In the present study, we demonstrated that exposure to high temperature in adult medaka males induce the activation of the juxtracrine signaling system of Notch in somatic cells, presumably Sertoli cells [44], surrounding type A spermatogonia. The inhibition of this pathway under thermal stress produced a fast loss of germ stem cells, supporting that the activation of the Notch pathway is essential for the maintenance of the germ line, ensuring the re-establishment of spermatogenic cycle.

Although increasing temperature promotes spermatogenesis by differentiation of spermatogonia [45], prolonged persistence at high temperatures causes reduction in the spermatogenic cell line due to an increase in apoptosis in most cells [46, 47], 
with the exception of type A spermatogonia [16, 47, 48]. These stem cells are kept in a quiescent state, a strategy that protects them from stress by inhibiting differentiation-activating signals, either intrinsic or mediated by cell-to-cell interactions [49-51]. For this reason, the interpretation of the mechanism that allows these cells to persist during stress would have important implications for understanding the reduction of male fertility, or even infertility. In our experimental model medaka, thermal stress showed to induce the loss of spermatogenic line, from spermatocytes to spermatozoa. This apoptotic induction was earlier observed by the up-regulation of apoptotic-related genes, such as p53 and bc/2, indicating that both the apoptotic and anti-apoptotic pathways are active under temperature stress. Apoptotic cells were observed in the medullary region of the testis, but not in the distal portion of the lobule, where spermatogonia are localized, establishing the protection of this cell type.

SSCs reside within the niche, a specialized microenvironment essential for their maintenance and self-renewal [2, 44, 52-54]. In medaka testis, the main components of the niche include SSCs directly surrounded by Sertoli cells that express sox9b [44, 55]. In the present work we observed the expression of the Notch pathway member Pen-2, a protein of the $\gamma$-secretase complex that is essential for the correct cleavage and signal transduction inside the cell [23]. Pen-2 mRNAs were restricted to the distal portion of the lobule during a thermal stress in presumptive Sertoli cells surrounding SSCs. Interestingly, Notch pathway has been observed to protect different cells from apoptosis [56]. On this regard, our observation would establish a cell-to-cell communication that protects the SSC from high temperature-induced apoptosis, with the Notch pathway holding an important role in such protective mechanism.

Apart from germ cell protection, the Notch signaling has been related to the regulation of self- renewing state and/or prevention of differentiation of SSCs through the negative regulation of glial cell line-derived neurotrophic factor (Gdnf), that is expressed in Sertoli cells [57, 58]. Gdnf has been implicated in the maintenance of the self-renewing state and/or prevention of differentiation of SSC thought the regulation of Nanos2, Stra8, Bcl6b, Cxcr4 and others in Aundiff spermatogonia [59-61]. Notch negative regulation of Gdnf occurs through the activation of germ cell-expressed Jag1 (jagged 1) $[53,57,58]$, a ligand that was highly expressed in our thermal treatment using medaka. In case of the receptor $\mathrm{NOTCH} 1$, it is expressed in undifferentiated germ cells and Sertoli cells of mouse testis whereas the ligand DIl4 is ubiquitously expressed in germ cells and in some Sertoli cells [62]. During embryogenesis, the constitutive activation of NOTCH1 signaling in Sertoli cells caused the exit of gonocyte from the quiescence status [26]. In flies, Notch signaling directly controls germline stem cell development and maintenance $[5,63]$, reinforcing the importance of cell-to-cell Notch signaling in the regulation of germ cell differentiation. Interestingly, although our results in medaka support the activation of the Notch pathway, including receptors, ligands, $\mathrm{y}$-secretase and the respective effectors of this pathway, the activation of Notch signals seems to work in the opposite direction to that described above, wherein the input signal (high temperature) seems to be sensed by SGa while the output seems to be in the somatic cells with a high expression of Pen-2, presumably Sertoli cells [44]. This differential activation by temperature in medaka would promote the protection through a state of quiescence and the concomitant inhibition of SGa differentiation. 


\section{Credit author statement}

ODMA: Conceptualization, Methodology, Analysis; AFB: Methodology and Visualization; RSH: WritingReviewing and Editing, JIF: Funding acquisition, Conceptualization, Investigation, Supervision; Writing- Original draft preparation, WritingReviewing and Editing.

\section{Declaration of Interest}

The authors have no conflict of interest.

\section{Acknowledgements}

We thank Tech. Gabriela C. López for helping with histological preparations. We also thank Dr. Tania Rodriguez for technical support and Tech. Javier Herdman (INTECH) for fish handling. We are grateful to NBRP Medaka (https://shigen.nig.ac.jp/medaka/) for providing HNI (Strain ID: MT835).

\section{Funding Sources}

This work was supported by the Agencia Nacional de Promoción Científica y Tecnológica Grant 2501/15 and 1875/18 (to JIF) and CONICET and São Paulo Research Foundation International Cooperation Grant D 2979/16 (to JIF and RSH). ODMA was supported by a PhD scholarship from the National Research Council (CONICET). AFB was supported by an undergraduate scholarship from Universidad Nacional de San Martín (UNSAM). JIF is members of the Research Scientist Career at the CONICET.

\section{References}

1. Schulz RW, de França LR, Lareyre JJ, et al (2010) Spermatogenesis in fish. Gen Comp Endocrinol 165:390-411. https://doi.org/10.1016/j.ygcen.2009.02.013

2. La HM, Hobbs RM (2019) Mechanisms regulating mammalian spermatogenesis and fertility recovery following germ cell depletion. Cell. Mol. Life Sci. 76:4071-4102. https://doi.org/ $10.1007 / \mathrm{s} 00018-019-03201-6$
3. Chiarini-Garcia H, Hornick JR, Griswold MD, Russell LD (2001) Distribution of type A spermatogonia in the mouse is not random. Biol Reprod 65:1179-1185. https://doi.org/10.1095/ biolreprod65.4.1179

4. de Rooij DG (2017) The nature and dynamics of spermatogonial stem cells. Development 144:3022 LP - 3030. https://doi.org/10.1242/dev.146571

5. Mclntyre DC, Nance J (2020) Niche Cell Wrapping Ensures Primordial Germ Cell Quiescence and Protection from Intercellular Cannibalism. Curr Biol 30:708-714.e4. https://doi.org/https:// doi.org/10.1016/j.cub.2019.12.021

6. Kitadate $\mathrm{Y}$, Kobayashi S (2010) Notch and Egfr signaling act antagonistically to regulate germ-line stem cell niche formation in Drosophila male embryonic gonads. Proc Natl Acad Sci 107:14241-14246. https://doi.org/10.1073/pnas.1003462107

7. Blackshaw AW, Massey PF (1978) The effect of cryptorchidism on the quantitative histology, histochemistry and hydrolytic enzyme activity of the rat testis. Aust J Biol Sci 31:5364. https://doi.org/10.1071/BI9780053

8. Mieusset R, Bujan L (1995) Testicular heating and its possible contributions to male infertility: a review. Int $\mathrm{J}$ Androl 18:169-184. https://doi.org/10.1111/j.1365-2605.1995.tb00408.x

9. Hutson J, Li R, Southwell B, et al (2013) Germ cell development in the postnatal testis: the key to prevent malignancy in cryptorchidism? Front. Endocrinol. (Lausanne). 3:176. https://doi.org/10.3389/fendo.2012.00176

10. Sarida M, Hattori RS, Zhang Y, et al (2019) Spatiotemporal Correlations between amh and cyp19a1a Transcript Expression and Apoptosis during Gonadal Sex Differentiation of Pejerrey, Odontesthes bonariensis. Sex Dev 13:99-108. https://doi.org/ 10.1159/000498997

11. Setchell BP (1998) The Parkes Lecture Heat and the testis. Reproduction 114:179-194. https://doi.org/10.1530/jrf.0.1140179 12. Hansen PJ (2009) Effects of heat stress on mammalian reproduction. Philos Trans R Soc B Biol Sci 364:3341-3350. https://doi.org/10.1098/rstb.2009.0131

13. Carlsen E (2003) History of febrile illness and variation in semen quality. Hum Reprod 18:2089-2092. https://doi.org/ 10.1093/humrep/deg412

14. Lue Y-H, Sinha Hikim AP, Swerdloff RS, et al (1999) Single exposure to heat induces stage-specific germ cell apoptosis in rats: role of intratesticular testosterone on stage specificity. Endocrinology 140:1709-1717. https://doi.org/10.1210/ endo.140.4.6629

15. Silva MA, Costa GMJ, Lacerda S, et al (2016) Successful xenogeneic germ cell transplantation from Jundia catfish (Rhamdia quelen) into adult Nile tilapia (Oreochromis niloticus) testes. Gen Comp Endocrinol 230:48-56. https://doi.org/10.1016/ j.ygcen.2016.03.012 
bioRxiv preprint doi: https://doi.org/10.1101/2021.06.10.447875; this version posted June 10, 2021. The copyright holder for this preprint (which was not certified by peer review) is the author/funder. All rights reserved. No reuse allowed without permission.

16. Ito LS, Cornejo AM, Yamashita M (2008) Thermal Threshold and Histological Process of Heat-Induced Sterility in Adult Pejerrey (Odontesthes bonariensis): A Comparative Analysis of Laboratory and Wild Specimens. 81:775-784. https://doi.org/ $10.1086 / 591035$

17. Hara K, Nakagawa T, Enomoto H, et al (2014) Mouse spermatogenic stem cells continually interconvert between equipotent singly isolated and syncytial states. Cell Stem Cell 14:658-672. https://doi.org/10.1016/j.stem.2014.01.019

18. Lin Y-T, Barske L, DeFalco T, Capel B (2017) Numb regulates somatic cell lineage commitment during early gonadogenesis in mice. Development 144:1607-1618. https://doi.org/10.1242/ dev. 149203

19. Bray SJ (2006) Notch signalling: a simple pathway becomes complex. Nat Rev Mol Cell Biol 7:678-689. https://doi.org/ $\underline{10.1038 / \mathrm{nrm} 2009}$

20. Henrique D, Schweisguth F (2019) Mechanisms of Notch signaling: a simple logic deployed in time and space. Development 146:dev172148. https://doi.org/10.1242/ dev.172148

21. Fortini ME (2002) $y$-Secretase-mediated proteolysis in cellsurface-receptor signalling. Nat Rev Mol Cell Biol 3:673-684. https://doi.org/10.1038/nrm910

22. Selkoe D, Kopan R (2003) NOTCH AND PRESENILIN: Regulated Intramembrane Proteolysis Links Development and Degeneration. Annu Rev Neurosci 26:565-597. https://doi.org/ 10.1146/annurev.neuro.26.041002.131334

23. Zhang Z, Nadeau $P$, Song $W$, et al (2000) Presenilins are required for $\gamma$-secretase cleavage of $\beta$-APP and transmembrane cleavage of Notch-1. Nat Cell Biol 2:463-465. https://doi.org/ $10.1038 / 35017108$

24. Kageyama R, Ohtsuka T, Kobayashi T (2007) The Hes gene family: repressors and oscillators that orchestrate embryogenesis. Development 134:1243-1251. https://doi.org/10.1242/ dev.000786

25. Fischer A, Gessler M (2007) Delta-Notch-and then? Protein interactions and proposed modes of repression by Hes and Hey bHLH factors. Nucleic Acids Res 35:4583-4596. https://doi.org/ $10.1093 / \mathrm{nar} / \mathrm{gkm} 477$

26. Garcia TX, DeFalco T, Capel B, Hofmann M-C (2013) Constitutive activation of NOTCH1 signaling in Sertoli cells causes gonocyte exit from quiescence. Dev Biol 377:188-201. https://doi.org/10.1016/j.ydbio.2013.01.031

27. Fernandino JI, Popesku JT, Paul-Prasanth B, et al (2011) Analysis of sexually dimorphic expression of genes at early gonadogenesis of pejerrey Odontesthes bonariensis using a heterologous microarray. Sex Dev 5:89-101. https://doi.org/ $10.1159 / 000324423$
28. dos Santos N, Silva M, Vale A (2008) Fish and Apoptosis: Studies in Disease and Pharmaceutical Design. Curr Pharm Des 14:170-183. https://doi.org/10.2174/138161208783378734

29. Campbell WA, Yang H, Zetterberg H, et al (2006) Zebrafish lacking Alzheimer presenilin enhancer 2 (Pen-2) demonstrate excessive p53-dependent apoptosis and neuronal loss. J Neurochem 96:1423-1440. https://doi.org/10.1111/ j.1471-4159.2006.03648.x

30. Xia W (2019) Y-Secretase and its modulators: Twenty years and beyond. Neurosci Lett 701:162-169. https://doi.org/10.1016/ j.neulet.2019.02.011

31. Nowell CS, Radtke F (2017) Notch as a tumour suppressor. Nat Rev Cancer 17:145-159. https://doi.org/10.1038/ nrc. 2016.145

32. Hiroshi O, Shinichi A, Yoshitake N (2003) Functional analysis of the p53 gene in apoptosis induced by heat stress or loss of stem cell factor signaling in mouse male germ cells. Biol Reprod 68:2249-2254. https://doi.org/10.1095/biolreprod.102.014779

33. Wabik A, Jones PH (2015) Switching roles: the functional plasticity of adult tissue stem cells. EMBO J 34:1164-1179. https://doi.org/10.15252/embj.201490386

34. Kadekar P, Roy R (2019) AMPK regulates germline stem cell quiescence and integrity through an endogenous small RNA pathway. PLOS Biol 17:e3000309. https://doi.org/10.1371/ journal.pbio.3000309

35. Kinoshita M, Murata K, Naruse K, Tanaka M (2012) Medaka: Biology, Management, and Experimental Protocols. WileyBlackwell.

36. Zhang Z, Hu J (2007) Development and Validation of Endogenous Reference Genes for Expression Profiling of Medaka (Oryzias latipes) Exposed to Endocrine Disrupting Chemicals by Quantitative Real-Time RT-PCR. Toxicol Sci 95:356-368. https:// doi.org/10.1093/toxsci/kfl161

37. Arias Padilla LF, Castañeda-Cortés DC, Rosa IF, et al (2021) Cystic proliferation of germline stem cells is necessary to reproductive success and normal mating behavior in medaka. eLife 10:e62757. https://doi.org/10.7554/eLife.62757

38. Wang D, Manali D, Wang T, et al (2011) Identification of pluripotency genes in the fish medaka. Int $\mathrm{J}$ Biol Sci 7:440. https://doi.org/10.7150/ijbs.7.440

39. Pfaffl MW (2001) A new mathematical model for relative quantification in real-time RT-PCR. Nucleic Acids Res 29:e45. https://doi.org/10.1093/nar/29.9.e45

40. Morinaga C, Saito D, Nakamura S, et al (2007) The hotei mutation of medaka in the anti-Müllerian hormone receptor causes the dysregulation of germ cell and sexual development. Proc Natl Acad Sci U S A 104:9691-9696. https://doi.org/ 10.1073/pnas.0611379104 
bioRxiv preprint doi: https://doi.org/10.1101/2021.06.10.447875; this version posted June 10, 2021. The copyright holder for this preprint (which was not certified by peer review) is the author/funder. All rights reserved. No reuse allowed without permission.

41. Zhou Y, Meng T, Wu L, et al (2020) Association between ambient temperature and semen quality: A longitudinal study of 10,802 men in China. Environ Int 135:105364. https://doi.org/ 10.1016/j.envint.2019.105364

42. Yogev L, Paz G, Kleiman SE, et al (2012) Freezability and Semen Parameters in Candidates of Sperm Bank Donors: 19922010. J Androl 33:999-1006. https://doi.org/10.2164/ jandrol.111.013045

43. Di Persio S, Saracino R, Fera S, et al (2017) Spermatogonial kinetics in humans. Development 144:3430 LP - 3439. https:// doi.org/10.1242/dev.150284

44. Nishimura T, Nakamura S, Tanaka M (2016) A structurally and functionally common unit in testes and ovaries of medaka (Oryzias latipes), a teleost fish. Sex Dev 10:159-165. https:// doi.org/10.1159/000447313

45. Alvarenga ÉR de, França LR de (2009) Effects of Different Temperatures on Testis Structure and Function, with Emphasis on Somatic Cells, in Sexually Mature Nile Tilapias (Oreochromis niloticus). Biol Reprod 80:537-544. https://doi.org/10.1095/ biolreprod.108.072827

46. Rockett JC, Mapp FL, Garges JB, et al (2001) Effects of Hyperthermia on Spermatogenesis, Apoptosis, Gene Expression, and Fertility in Adult Male Mice. Biol Reprod 65:229-239. https:// doi.org/10.1095/biolreprod65.1.229

47. Ito LS, Takahashi C, Yamashita M, Strüssmann CA (2008) Warm water induces apoptosis, gonadal degeneration, and germ cell loss in subadult pejerrey Odontesthes bonariensis (Pisces, Atheriniformes). Physiol Biochem Zool 81:762-774. https:// doi.org/10.1086/590219

48. Majhi SK, Hattori RS, Rahman SM, et al (2009) Experimentally induced depletion of germ cells in sub-adult Patagonian pejerrey (Odontesthes hatcheri). Theriogenology $71: 1162-1172$. https://doi.org/10.1016/ j.theriogenology.2008.12.008

49. Zhou Z, Kawabe H, Suzuki A, et al (2017) NEDD4 controls spermatogonial stem cell homeostasis and stress response by regulating messenger ribonucleoprotein complexes. Nat Commun 8:15662. https://doi.org/10.1038/ncomms15662

50. Liao H-F, Chen WSC, Chen Y-H, et al (2014) DNMT3L promotes quiescence in postnatal spermatogonial progenitor cells. Development 141:2402 LP - 2413. https://doi.org/10.1242/ dev.105130

51. Chen J, Cai T, Zheng C, et al (2017) MicroRNA-202 maintains spermatogonial stem cells by inhibiting cell cycle regulators and RNA binding proteins. Nucleic Acids Res 45:41424157. https://doi.org/10.1093/nar/gkw1287

52. Nóbrega $\mathrm{RH}$, Greebe $\mathrm{CD}$, van de Kant $\mathrm{H}$, et al (2010) Spermatogonial stem cell niche and spermatogonial stem cell transplantation in zebrafish. PLoS One 5:1-16. https://doi.org/ 10.1371/journal.pone.0012808

53. Mäkelä J-A, Hobbs RM (2019) Molecular regulation of spermatogonial stem cell renewal and differentiation. Reproduction 158:R169-R187. https://doi.org/10.1530/ REP-18-0476

54. Losick VP, Morris LX, Fox DT, Spradling A (2011) Drosophila Stem Cell Niches: A Decade of Discovery Suggests a Unified View of Stem Cell Regulation. Dev Cell 21:159-171. https:// doi.org/10.1016/j.devcel.2011.06.018

55. Nakamura S, Watakabe I, Nishimura T, et al (2012) Analysis of medaka sox 9 orthologue reveals a conserved role in germ cell maintenance. PLoS One 7:e29982. https://doi.org/10.1371/ journal.pone.0029982

56. Chadwick N, Zeef L, Portillo V, et al (2010) Notch protection against apoptosis in T-ALL cells mediated by GIMAP5. Blood Cells, Mol Dis 45:201-209. https://doi.org/10.1016/ j.bcmd.2010.07.006

57. Garcia TX, Farmaha JK, Kow S, Hofmann M-C (2014) RBPJ in mouse Sertoli cells is required for proper regulation of the testis stem cell niche. Development 141:4468 LP - 4478. https:// doi.org/10.1242/dev.113969

58. Garcia TX, Parekh P, Gandhi P, et al (2017) The NOTCH Ligand JAG1 Regulates GDNF Expression in Sertoli Cells. Stem Cells Dev 26:585-598. https://doi.org/10.1089/scd.2016.0318

59. Chen C, Ouyang W, Grigura V, et al (2005) ERM is required for transcriptional control of the spermatogonial stem cell niche. Nature 436:1030-1034. https://doi.org/10.1038/nature03894

60. Oatley JM, Avarbock MR, Telaranta Al, et al (2006) Identifying genes important for spermatogonial stem cell selfrenewal and survival. Proc Natl Acad Sci 103:9524 LP - 9529. https://doi.org/10.1073/pnas.0603332103

61. Sada A, Hasegawa K, Pin PH, Saga Y (2012) NANOS2 Acts Downstream of Glial Cell Line-Derived Neurotrophic Factor Signaling to Suppress Differentiation of Spermatogonial Stem Cells. Stem Cells 30:280-291. https://doi.org/https://doi.org/ 10.1002/stem.790

62. Murta D, Batista M, Silva E, et al (2013) Dynamics of Notch Pathway Expression during Mouse Testis Post-Natal Development and along the Spermatogenic Cycle. PLoS One 8:e72767. https://doi.org/10.1371/journal.pone.0072767

63. Kimble J, Crittenden SL (2007) Controls of Germline Stem Cells, Entry into Meiosis, and the Sperm/Oocyte Decision in Caenorhabditis elegans. Annu Rev Cell Dev Biol 23:405-433. https://doi.org/10.1146/annurev.cellbio.23.090506.123326 


\section{Supplementary Files}

A. $p 53$

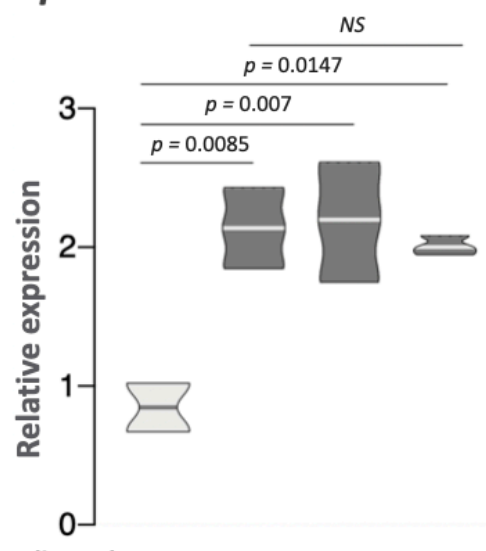

B. hes1

$p=0.001$

\begin{tabular}{c}
$\frac{p=0.001}{p=0.002}$ \\
\hline$p=0.005$ \\
$p=0.014$
\end{tabular}

2.5
2.0
$.5-$
.0
$0.5-$
0.0

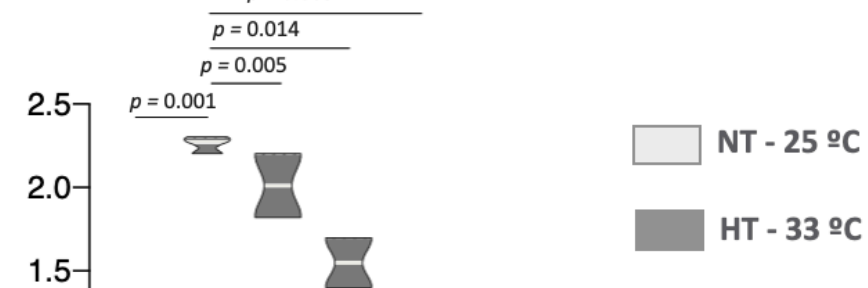

Figure Supplement 1. Time and doses optimization to ex vivo experiment. Time exposure curve of p53 transcript abundance in testis explants incubated at control (NT $-25^{\circ} \mathrm{C}$, light grey) and high ( $\mathrm{HT}-33^{\circ} \mathrm{C}$, dark grey) temperature and sampled at $0,3,12$ and 24 hours (A). DAPT doses response: Transcript abundance levels of hes1 (Notch pathway cis target genes) in adult testis explants incubated during 24 hours at $0,6.25,12.5,25,50$ and $100 \mu \mathrm{M}$ of DAPT ( $\gamma$-secretase inhibitor) (B). Transcript abundance quantification was performed using the $2-\Delta \Delta \mathrm{Ct}$ method and p53 and hes 1 values were normalized to rpl7. p-values are indicated when transcript abundance between treatment at the same sampling day differ significantly $(P<0.05)$. NS, not statistically significant. Relative gene expression levels were compared as described by Pfaffl [39].

\begin{tabular}{|c|c|c|c|}
\hline Gene symbol & Accession Number & primer sequence $\left(5^{\prime}-3\right)$ & Experiment \\
\hline oct4 & ENSORLG00000010471.2 & $\begin{array}{l}\text { Fw: GGCCCCGGCTTTCTTTG } \\
\text { Rv: CTCCGCTTCCTCTTCCTGGTG }\end{array}$ & WMISH \\
\hline$a m h$ & NM_001104728.1 & $\begin{array}{l}\text { Fw: ACGCCACTTCTGCTTTTCAC } \\
\text { Rv: AAGTCCACAACATCCGCTTG }\end{array}$ & \multirow{14}{*}{ RT-qPCR } \\
\hline notch1a & ENSORLT00000006535 & $\begin{array}{l}\text { Fw: AAGGTGTGGAGGTGAACCAG } \\
\text { Rv: GTCGGTACAGGTTGCTCCAT }\end{array}$ & \\
\hline notch3 & ENSORLG00000005980 & $\begin{array}{l}\text { Fw: ATCGCAAAGCCAATGACAGC } \\
\text { Rv: ATGGGGTTTGTGCAATTGGC }\end{array}$ & \\
\hline dl14 & ENSORLG00000016743 & $\begin{array}{l}\text { Fw: AGCAAGCCTTGTTACAACGG } \\
\text { Rv: TCAAACCCATTTGCGCACAC }\end{array}$ & \\
\hline Jag1a & ENSORLG00000012175 & $\begin{array}{l}\text { Fw: AACATCGATGACTGCAGCAC } \\
\text { Rv: TGCACGTTGCTTCATCACAC }\end{array}$ & \\
\hline Jag1b & ENSORLG00000000972 & $\begin{array}{l}\text { Fw: TGTCAACGCCAAATCATGCC } \\
\text { Rv: ACCGTTCACCAAATCCTTGC }\end{array}$ & \\
\hline Jag2a & ENSORLG00000017877 & $\begin{array}{l}\text { Fw: TTGCAAAGAAGGCTGGGAAG } \\
\text { Rv: TGCACATTCACAGCGAAACC }\end{array}$ & \\
\hline Jag2b & ENSORLG00000017729 & $\begin{array}{l}\text { Fw: TGTGTGAACGCTAACGCTTG } \\
\text { Rv: TTGCATGTTGCCCCATTCTG }\end{array}$ & \\
\hline oct4 & ENSORLG00000010471.2 & $\begin{array}{l}\text { Fw: TTGAGCGCGTATTTGCTGAC } \\
\text { Rv: ACTTGATGAAGTACGCCTCCCAG }\end{array}$ & \\
\hline p53 & NM_001104742.1 & $\begin{array}{l}\text { Fw: TGCCAGCTTGCAAAAACCAG } \\
\text { Rv: AGAGTCCTCGTTTTGGTGGTG }\end{array}$ & \\
\hline$R P L 7$ & ENSORLG00000007967.2 & $\begin{array}{l}\text { Fw: CGCCAGATCTTCAACGGTGTAT } \\
\text { Rv: AGGCTCAGCAATCCTCAGCAT }\end{array}$ & \\
\hline$b c / 2$ & XM_004079356.2 & $\begin{array}{l}\text { Fw: TATCGCGTTCTTCGAGTTCG } \\
\text { Rv: TCAATCCAGCTGTTGAGAGGTC }\end{array}$ & \\
\hline pen2 & ENSDARG00000068698 & $\begin{array}{l}\text { Fw: ATTACTTGGGAGGCTTTGCG } \\
\text { Rv: TGCAGCTGTTCAGTGTAAGC }\end{array}$ & \\
\hline hes1 & XM_004074234.2 & $\begin{array}{l}\text { Fw: GGGACTTTTTGCCAGTTTGA } \\
\text { Rv: TTTGTCGGGAGTTGTGTTCA }\end{array}$ & \\
\hline
\end{tabular}

Table Supplement 1. Primers sequences, ENSEMBL and NCBI accession numbers and respective references of each gene were added. 